\title{
Proceeding
}

Supplementary Issue: Winter Conferences of Sports Science. Costa Blanca Sports Science Events, 22-23 March 2021. Alicante, Spain.

\section{The effects of beta (2)-adrenergic receptors activation on the cardiovascular system and on the skeletal muscle: A narrative review}

VERONICA ROMANO, DOMENICO COZZOLINO, GIORGIO ZINNO, STEFANO PALERMI, DOMIZIANO TARANTINO

Department of Public Health, University Federico II of Naples, Italy

\begin{abstract}
Beta(2)-adrenergic receptors (adrenoceptors) are activated by the catecholamines norepinephrine and epinephrine. Adrenoceptors are found in different tissues, such as smooth muscle, skeletal muscle and myocardium. Stimulation of adrenoceptors is implicated in several physiological functions in the body, such as bronchodilation, increased perfusion and vasodilation. The latters, together with increased muscular mass and contraction speed, facilitate muscle's motility and contraction. In the cardiovascular system, the activation of adrenoceptors increases heart muscle contraction, cardiac output and heart rate. Some studies also suggested a cardioprotective role of the stimulation of adrenoceptors. Beta(2)-adrenergic receptors agonists, principally divided in long-acting beta(2) agonists (LABAs) and short-acting beta(2) agonists (SABAs), are primarily used to treat asthma and other pulmonary disorders. Beta(2)-adrenergic receptors activation has been correlated with anabolic properties and muscular hypertrophy with the use of oral clenbuterol, as well as intravenous albuterol. Given these anabolic, lipolytic and performance-enhancing effects, LABAs are frequently abused by athletes. For this reason, most of these drugs are banned by the World Anti-Doping Agency, or admissible only with limitations. The aim of this narrative review is to report the results of some recent studies about the effects of beta(2)-adrenergic receptors activation on the cardiovascular system and on the skeletal muscle.

Keywords: Beta(2)-adrenergic receptors; Beta(2)-agonist; Catecholamines; Cardiovascular system; Skeletal muscle; Doping.

Cite this article as:

Romano, V., Cozzolino, D., Zinno, G., Palermi, S., \& Tarantino, D. (2021). The effects of beta (2)-adrenergic receptors activation on the cardiovascular system and on the skeletal muscle: A narrative review. Journal of Human Sport and Exercise, 16(3proc), S1373-S1383. https://doi.org/10.14198/jhse.2021.16.Proc3.53

Corresponding author. Department of Public Health, University Federico II of Naples, Italy.

E-mail: domiziano22@gmail.com

Abstract submitted to: Winter Conferences of Sports Science. Costa Blanca Sports Science Events, 22-23 March 2021. Alicante, Spain.

JOURNAL OF HUMAN SPORT \& EXERCISE ISSN 1988-5202.

(c) Faculty of Education. University of Alicante.

doi:10.14198/jhse.2021.16.Proc3.53
\end{abstract}




\section{INTRODUCTION}

Beta-2 (B2)-adrenergic receptor (ar) is a subtype of adrenergic receptors which binds several endogenous hormones such as the catecholamines norepinephrine and epinephrine, resulting in several types of responses. $\beta 2$-ar is mainly expressed in the airways and in the vascular smooth muscle, but some studies also found its presence in the myocardium, although the $\beta 1$-ar subtype is the most expressed in heart (Brodde et al., 2006).

ß2-ar selective agonists are derived from the chemical structure of adrenaline. They are traditionally used for the treatment of bronchospasm associated with asthma and the treatment of symptomatic patient with chronic obstructive pulmonary disease (COPD) to induce a bronchodilatation by relaxing airway smooth muscle (Cazzola et al., 1997).

Stimulation of adrenoceptors is also implicated in muscle's contraction and motility. This happens through a mechanism of increased perfusion and vasodilation of blood vessels to skeletal muscle, but also through a mechanism of increased mass and contraction speed (Rang et al., 2003).

The skeletal muscle's microvasculature response to $\beta 2$-ar stimuli was recently found to be diminished with cardiac surgery (Ziegler et al., 2020).

It has been widely accepted that activation of muscle $\beta 2$-ars with the use of $\beta_{2}$-ar agonists, principally divided in long-acting $\beta 2$-agonists (LABAs) and short-acting $\beta 2$-agonists (SABAs), leads to muscle hypertrophy and skeletal muscle repair in vivo (Chikazawa and Sato, 2018b; Jean-Baptiste et al., 2005; Sato et al., 2011).

LABAs, such as clenbuterol, are frequently abused performance-enhancing drugs for their anabolic, lipolytic, and performance-enhancing effects (Davis et al., 2008). SABAs, such as albuterol, were not found to generate the same impacts on muscle mass if administered orally, suggesting that drugs with a short halflife are not able to achieve these effects unless they are administered by intravenous route (Choo et al., 1992; Kamalakkannan et al., 2008). Indeed, the use by athletes of $\beta 2$-ar agonists such as clenbuterol is strictly prohibited, and it would be considered a doping violation (Chikazawa and Sato, 2018b), since these drugs are banned by the World Anti-Doping Agency, though some are permissible under a therapeutic use exemption (such as for asthma).

Recent studies reported the correlation of a different expression of $\beta 2$-ar in the myocardium and heart diseases, potentially allowing to detect new markers of myocardium infarction. Moreover, $\beta 2$-ar can be a potential therapy target for several heart diseases (Li et al., 2019; Xia et al., 2017). In addition, $\beta 2$-ars are also present on endothelial cells where they modulate vasodilation and angiogenesis (Chisholm et al., 2012; Guimarães and Moura, 2001).

Several studies investigated the role of $\beta 2$-ar agonists as pharmacologic agents aimed at reversing pathological conditions associated with skeletal muscle wasting such as sarcopenia and frailty (Kim et al., 2018,2020 ). Even in the case of severe muscle wasting, such as after a spinal cord injury, a role for systemic 32 -ar-mediated mitochondrial biogenesis in improving skeletal muscle recovery was found (Scholpa et al., 2019).

In this review we will report the results of some recent studies about the effects of $\beta 2$-ar activation on the cardiovascular system and on the skeletal muscle. 


\section{STRUCTURE AND PATHWAYS RELATED TO THE $\beta 2$-ADRENERGIC RECEPTOR'S ACTIVATION}

The $\beta 2$-ars are a subtype of $\beta$-adrenergic receptors, belonging to the superfamily $G$ protein coupled receptors (GPCR). GPCRs have a conserved core of seven transmembrane a-helices that are connected by three extracellular and intracellular loops. Some of these receptors are known as potent inducers of hypertrophy (Berdeaux and Stewart, 2012), and there is evidence about the importance of the regulation of the activation of GPCRs for the maintenance of skeletal muscle function (Chikazawa and Sato, 2018b). They transduce a signal from the extracellular environment to the intracellular ones. The signal transduction starts with the binding of an endogenous hormone (epinephrine and norepinephrine for the adrenergic receptors) leading to a conformation change that activate the intramembrane protein $G$, an heterotrimer with three subunits: $\alpha$, $\beta, \gamma$. The activation of $G$ protein leads to a loss of affinity of GDP for GTP with the consequently dissociation of the heterotrimer $\mathrm{Ga}$ and $\mathrm{G} \beta \mathrm{y}$ active subunits, mediating the intracellular signal transduction. Ga subunits are grouped in 4 subfamilies: $\mathrm{Ga}_{\mathrm{s}}, \mathrm{Ga}_{\mathrm{i}}, \mathrm{Ga}_{\mathrm{q}}$ and $\mathrm{Ga}_{12}$. These different subunits modulate the release of a second messenger in the cytoplasm. $\beta$-ars are mainly associated with $G$ stimulating $\left(G_{s}\right)$, leading to the activation of adenylate cyclase with the consequent increasing of cyclic adenosine monophosphate, cAMP, which activates cAMP dependent-kinases protein kinase A (PKA). PKA phosphorylates troponin I and $\mathrm{Ca}^{2+}$ channel, activating it, and finally inducing organism response (Freedman and Lefkowitz, 2004).

Intracellular CAMP enhances CAMP-response element binding protein (CREB) phosphorylation and CREB target gene expression, which is assumed to be critical for myogenic differentiation and myofiber survival. Gai-coupled receptors activate both the PI3K-AKT and mTOR signalling pathway, resulting in an increase in muscle protein synthesis (Minetti et al., 2011). The 3'-phosphoinositide-dependent kinase 1 (PDK1), a key component of $\mathrm{PI} 3 \mathrm{~K}$ signalling pathway, was found to regulate skeletal muscle mass under the static condition and that it contributes to mechanical load-induced muscle hypertrophy, at least in part by mediating signalling from $\beta 2$-ar (Kuramoto et al., 2021).

A common genetic variant in the $\beta 2$-ar, the Arg16Gly genotype was found to have a significant effect on fatfree mass, muscle strength and motor unit behaviour in recreationally trained men (Jenkins et al., 2018). These data might have important clinical and exercise-related implications. For example, $\beta 2-A R$ (rs1042713) genotype might influence the responsiveness of skeletal muscle to clinical or exercise-based interventions or $\beta$-ar agonist treatment (Jenkins et al., 2018).

\section{RELATIONSHIP BETWEEN LOCALIZATION AND FUNCTION OF $\beta 2$-ADRENERGIC RECEPTORS IN THE CARDIOVASCULAR SYSTEM}

$\beta 2$-ars are estimated to be the $25 \%$ of all adrenergic receptors in myocardium, while $\beta 1$-ars are the most expressed adrenergic receptors in the heart (75\%) (Brodde et al., 2006). $\beta 1$-ars are the most expressed adrenergic receptor in the cardiomyocyte, while $\beta 2$-ars are mainly expressed in cardiac fibroblasts, where they modulate collagen secretion and fibroblast autophagy, although the mechanism is still not totally understood (Bristow et al., 1986; Meszaros et al., 2000).

New findings were available in the last two decades for $\beta$-ar signalling. In the classic linear model, $\beta$-ars were thought to primarily mediate cardiac functions such as inotropy, chronotropy, and lusitropy through the activation of stimulating $G_{s}$ pathway, activating the adenylate cyclase which increases cAMP's intracellular concentration (Guimarães and Moura, 2001; Xia et al., 2017). Increased cAMP's concentration leads to the activation of PKA, which phosphorylates several downstream proteins like calcium ATPase enhancing intracellular calcium concentration with a consequent increase of heart contractions and blood flow rate 
(Bernstein et al., 2011). The presence of both $\beta 1$ and $\beta 2$ adrenergic receptors in the heart generates a difference in the cAMP local concentration depending on the spatial localization of adrenergic receptors. $\beta 2$ ar was also found to be localized in caveolae, an invagination of plasma membrane enriched in cholesterol, glycophospholipids, so this could be associated to a cardioprotective effect of $\beta 2$-ars (Agarwal et al., 2011; Bernstein et al., 2011; Head et al., 2005; Woo and Xiao, 2012; Xiang et al., 2002; Zhu et al., 2001).

\section{EFFECT OF $\beta 2$ - ADRENERGIC RECEPTOR'S ACTIVATION ON THE CARDIOVASCULAR SYSTEM}

Recent studies found that, unlike $\beta 1$-ar, $\beta 2$-ar can activate both $G_{s}$ and $G_{i}$ pathways, decreasing cAMP concentration, and activating another pathway inhibiting cardiomyocytes apoptosis with a cardioprotective effect (Santos and Spadari-Bratfisch, 2006). Another study underlined the cardioprotective effect of an overstimulation of $\beta 2$-ars, regulating macrophage activation and decreasing the possibility to develop heart injuries (Noh et al., 2017). The role of extracellular matrix (ECM) has been shown to be pivotal in cardiac regeneration and repair after cardiac injury (Castaldo et al., 2013; Belviso et al., 2020a; Belviso et al., 2020b), and a recent study discovered that $\beta 2$-ars are also involved in the maintenance of the cardiac matrix's homeostasis, modulating collagen secretion and fibroblast autophagy, so that might contribute to prevent fibrosis due to pathological adrenergic stimulation (Aránguiz-Urroz et al., 2011). Another study underlined the cardioprotective effect of $\beta 2$-ar stimulation, activating pro-survival kinases and reducing mitochondrial disfunction; in fact, $\beta 2$-ar knock up enhances cardiotoxicity downregulating survival kinases and damaging the mitochondrial membrane (Fajardo et al., 2011).

In contrast with the $\beta 2$ cardioprotective effect, some studies revealed a relationship between heart failure and over-stimulation of $\beta 2$-ar in subject with type- 2 diabetes, since $\beta 2$-ar antagonists were found to reduce heart complications in type-2 diabetes. These findings could contribute to discover a new therapeutic target in $\beta 2$ ar preventing and treating type-2 diabetes associated cardiac disfunction (Rybin et al., 2000; Spadari et al., 2018; Wang et al., 2017; Wright et al., 2014). $\beta 2$-ar was found to be involved in the modulation of vasodilation via $G_{\text {as }} / A C / P K A$ pathway trough the activation of the endothelial nitric oxide synthase. Furthermore, $\beta 2$-ar stimulation was found to be related to the activation of the vascular endothelial growth factor and the basic fibroblast growth factor, both activating proangiogenic pathways (D'Angelo et al., 1997; laccarino et al., 2005; Storch and Hoeger, 2010). A recent study has revealed that $\beta 2$-ar is overexpressed in infantile haemangioma, so it might be used as predictive marker and a preventive therapy target of vascular cancer (Chisholm et al., 2012).

\section{EFFECT OF ß2- ADRENERGIC RECEPTOR'S ACTIVATION ON THE MUSCULOSKELETAL SYSTEM}

Skeletal muscle mass is controlled by balancing protein synthesis and degradation (Chikazawa \& Sato, 2018a). Decreased protein synthesis and/or increased protein degradation for a prolonged period of time, which may be caused by inactivity, inadequate diet, reduced hormone levels or disease, contribute to a decrease in skeletal muscle mass and the onset of atrophy (Chikazawa \& Sato, 2018a; Toledo et al., 2016).

The hypertrophy and anti-atrophy effects of $\beta 2$-ar-agonists can be explained by their actions on the balance between protein synthesis and protein degradation (Joassard et al., 2013). Previous studies indicate that chronic administration of $\beta 2$-ar-agonists not only increases muscle protein synthesis, but also decreases muscle protein degradation (Busquets et al., 2004; Koopman et al., 2010; Navegantes et al., 2000, 2001, 2004). 
ß2-ar agonist clenbuterol administration was found to improve skeletal muscle atrophy induced by hindlimb unweighting, denervation, and dexamethasone treatment through the activation of protein synthesis and inhibition of protein degradation by controlling lysosomal and proteasomal activity in animal models (Chikazawa and Sato, 2018a; Gonçalves et al., 2011; Pellegrino et al., 2004; Yimlamai et al., 2005).

The preclinical data reported in a study by Koziczak-Holbro et al. (Koziczak-Holbro et al., 2019) showed that a novel 5-hydroxybenzothiazolone (5-HOB) derived b2-ar agonist is a strong, selective $\beta 2$-ar agonist that is effective in promoting skeletal muscle growth, displaying tissue selectivity and reduced cardiovascular effects, compared with the well-described formoterol. Hence, their results suggested that 5 -HOB may provide a new valuable treatment option for muscle atrophy conditions (Koziczak-Holbro et al., 2019).

Therefore, $\beta 2$-ar agonists clearly have the potential to augment skeletal muscle mass and function (Jenkins et al., 2018). Kamalakkannan et al. (Kamalakkannan et al., 2008) observed a significant increase in lean mass and maximal strength after clenbuterol administration in chronic heart failure patients. Jessen et al. (Jessen et al., 2018) observed a $1.03 \mathrm{~kg}$ increase in lean body mass after only four weeks of daily inhaled terbutaline compared with placebo administration in healthy young men. Le Panse et al. (Le Panse et al., 2005) observed important increases in peak power during maximal cycling exercise after three weeks of salbutamol ingestion in trained and untrained males.

Hostrup et al. (Hostrup et al., 2015) observed a significant $1.95 \mathrm{~kg}$ increase in lean body mass, in addition to increased cross-sectional area of type I and type II fibres of the vastus lateralis, and an increase in maximal strength and in peak power during maximal cycling exercise after four weeks of twice daily oral terbutaline versus placebo administration in trained, healthy young men.

Kim at al. (Kim et al., 2018) found out that the increase in skeletal muscle fibre size with chronic clenbuterolinduced $\beta 2$-ar stimulation was $\beta$-arrestin 1-dependent, indicating that $\beta$-arrestin 1 is a critical signalling molecule regulating skeletal muscle growth and function downstream of the $\beta 2$-ar.

The role of $\beta$-arrestin 1 was also studied with the use of carvedilol, a $\beta$-ar antagonist, widely used for the treatment of chronic systolic heart failure and hypertension. In a murine model, Kim et al. (Kim et al., 2020) showed that chronic treatment with carvedilol enhanced contractile force in skeletal muscle, and this process was mediated by $\beta$-arrestin 1. Carvedilol enhanced skeletal muscle contractility despite a lack of effect on skeletal muscle hypertrophy. So, these findings suggested a potential unique clinical role of carvedilol to stimulate skeletal muscle contractility while avoiding the adverse effects with $\beta$-ar agonists.

A couple of recent studies by Chikazawa and Sato (Chikazawa and Sato, 2018a, 2018b) showed that it is also possible to increase muscle $\beta 2$-ar expression by dietary improvement, so this was thought to be a promising strategy for the maintenance of healthy skeletal muscle and for achieving muscle hypertrophy. Resveratrol (a polyphenolic compound) and genistein (an isoflavone found in soybean) were shown to increase the $\beta 2$-ar mRNA levels in skeletal muscle cells (Chikazawa and Sato, 2018b). Gramine (a natural indole alkaloid) and hordenine (an alkaloid of the phenethylamine class), if administered by intramuscular route, were shown to increase the expression of hypertrophic genes in mice quadriceps, which was suggested to have been mediated, at least in part, by the $\beta 2$-ar activation, giving new possible therapeutic options (Chikazawa and Sato, 2018a). 


\section{DISCUSSION AND CONCLUSIONS}

Collectively, there is a strong evidence supporting the importance of the $\beta 2$-ar in the heart. Although $\beta 1$-ar is the main modulator of the cardiac muscle's contraction, this mechanism is also involved in several heart disfunctions (Noh et al., 2017). $\beta 2$-ar was found to potentially enhance heart contractions without the negative effects seen through the overstimulation of $\beta 1$-ar (Bernstein et al., 2011).

The data reviewed here suggested that $\beta 2$-ar's activation has some beneficial effects on the heart, such as a cardioprotective effect due to the alternative activation of $\beta 2-a / G_{i} / P I 3 K$ pathway that leads to a decrease in cardiomyocyte apoptosis (Li et al., 2019). Therefore, $\beta 2$-ars represent a potential therapeutic target for the treatment of cardiac diseases and vascular tumours (Aránguiz-Urroz et al., 2011; Rybin et al., 2000; Storch and Hoeger, 2010). However, further studies are needed to understand the intracellular signalling regulated by $\beta 2$-ars, so then its use could be extended to treat a variety of cardiovascular diseases.

Maintaining skeletal muscle mass and function is vital for ameliorating the quality of life of elderly people (Chikazawa and Sato, 2018b). The data from the reported studies suggested that $\beta 2$-ar agonists could be used as pharmacologic agents to prevent skeletal muscle wasting, increasing muscle mass and preventing atrophy (Chikazawa and Sato, 2018a).

Anyway, since most of those studies were performed in vitro, further studies are needed before they could be effectively proposed to be used in vivo.

\section{REFERENCES}

Agarwal, S. R., MacDougall, D. A., Tyser, R., Pugh, S. D., Calaghan, S. C., \& Harvey, R. D. (2011). Effects of cholesterol depletion on compartmentalized cAMP responses in adult cardiac myocytes. Journal of Molecular and Cellular Cardiology, 50(3), 500-509. https://doi.org/10.1016/j.yimcc.2010.11.015

Aránguiz-Urroz, P., Canales, J., Copaja, M., Troncoso, R., Vicencio, J. M., Carrillo, C., Lara, H., Lavandero, S., \& Díaz-Araya, G. (2011). Beta2-adrenergic receptor regulates cardiac fibroblast autophagy and collagen degradation. Biochimica et Biophysica Acta (BBA) - Molecular Basis of Disease, 1812(1), 23-31. https://doi.org/10.1016/j.bbadis.2010.07.003

Belviso, I., Angelini, F., Di Meglio, F., Picchio, V., Sacco, AM., Nocella, C., Romano, V., Nurzynska, D., Frati, G., Maiello, C., Messina, E., Montagnani, S., Pagano, F., Castaldo, C., Chimenti, I. (2020a). The Microenvironment of Decellularized Extracellular Matrix from Heart Failure Myocardium Alters the Balance between Angiogenic and Fibrotic Signals from Stromal Primitive Cells. Int J Mol Sci, 21(21):7903. https://doi.org/10.3390/ijms21217903

Belviso, I., Romano, V., Sacco, AM., Ricci, G., Massai, D., Cammarota, M., Catizone, A., Schiraldi, C., Nurzynska, D., Terzini, M., Aldieri, A., Serino, G., Schonauer, F., Sirico, F., D'Andrea, F., Montagnani, S., Di Meglio, F., Castaldo, C. (2020b). Decellularized Human Dermal Matrix as a Biological Scaffold for Cardiac Repair and Regeneration. Front Bioeng Biotechnol, 20;8:229. http://doi.org/10.3389/fbioe.2020.00229

Berdeaux, R., \& Stewart, R. (2012). cAMP signaling in skeletal muscle adaptation: Hypertrophy, metabolism, and regeneration. American Journal of Physiology. Endocrinology and Metabolism, 303(1), E1-17. https://doi.org/10.1152/ajpendo.00555.2011 
Bernstein, D., Fajardo, G., \& Zhao, M. (2011). The role of $\beta$-adrenergic receptors in heart failure: differential regulation of cardiotoxicity and cardioprotection. Progress in Pediatric Cardiology, 31(1), 35-38. https://doi.org/10.1016/j.ppedcard.2010.11.007

Bristow, M. R., Ginsburg, R., Umans, V., Fowler, M., Minobe, W., Rasmussen, R., Zera, P., Menlove, R., Shah, P., \& Jamieson, S. (1986). Beta 1- and beta 2-adrenergic-receptor subpopulations in nonfailing and failing human ventricular myocardium: Coupling of both receptor subtypes to muscle contraction and selective beta 1-receptor down-regulation in heart failure. Circulation Research, 59(3), 297-309. https://doi.org/10.1161/01.res.59.3.297

Brodde, O.-E., Bruck, H., \& Leineweber, K. (2006). Cardiac adrenoceptors: Physiological and pathophysiological relevance. Journal of Pharmacological Sciences, 100(5), 323-337. https://doi.org/10.1254/jphs.cri06001x

Busquets, S., Figueras, M. T., Fuster, G., Almendro, V., Moore-Carrasco, R., Ametller, E., Argilés, J. M., \& López-Soriano, F. J. (2004). Anticachectic effects of formoterol: A drug for potential treatment of muscle wasting. Cancer Research, 64(18), 6725-6731. https://doi.org/10.1158/0008-5472.CAN-04$\underline{0425}$

Castaldo, C., Di Meglio, F., Miraglia, R., Sacco, AM., Romano, V., Bancone, C., Della Corte, A., Montagnani, S., Nurzynska, D. (2013). Cardiac fibroblast-derived extracellular matrix (biomatrix) as a model for the studies of cardiac primitive cell biological properties in normal and pathological adult human heart. Biomed Res Int, 2013:352370. http://doi.org/10.1155/2013/352370

Cazzola, M., Spina, D., \& Matera, M. G. (1997). The use of bronchodilators in stable chronic obstructive pulmonary disease. Pulmonary Pharmacology \& Therapeutics, 10(3), 129-144. https://doi.org/10.1006/pupt.1997.0087

Chikazawa, M., \& Sato, R. (2018a). Identification of Functional Food Factors as $\beta 2$-Adrenergic Receptor Agonists and Their Potential Roles in Skeletal Muscle. Journal of Nutritional Science and Vitaminology, 64(1), 68-74. https://doi.org/10.3177/jnsv.64.68

Chikazawa, M., \& Sato, R. (2018b). Identification of a Novel Function of Resveratrol and Genistein as a Regulator of $\beta 2$-Adrenergic Receptor Expression in Skeletal Muscle Cells and Characterization of Promoter Elements Required for Promoter Activation. Molecular Nutrition \& Food Research, 62(22), e1800530. https://doi.org/10.1002/mnfr.201800530

Chisholm, K. M., Chang, K. W., Truong, M. T., Kwok, S., West, R. B., \& Heerema-McKenney, A. E. (2012). $\beta$-Adrenergic receptor expression in vascular tumors. Modern Pathology: An Official Journal of the United States and Canadian Academy of Pathology, Inc, 25(11), 1446-1451. https://doi.org/10.1038/modpathol.2012.108

Choo, J. J., Horan, M. A., Little, R. A., \& Rothwell, N. J. (1992). Anabolic effects of clenbuterol on skeletal muscle are mediated by beta 2-adrenoceptor activation. The American Journal of Physiology, 263(1 Pt 1), E50-56. https://doi.org/10.1152/ajpendo.1992.263.1.E50

D'Angelo, G., Lee, H., \& Weiner, R. I. (1997). CAMP-dependent protein kinase inhibits the mitogenic action of vascular endothelial growth factor and fibroblast growth factor in capillary endothelial cells by blocking Raf activation. Journal of Cellular Biochemistry, 67(3), 353-366. https://doi.org/10.1002/(SICI)1097-4644(19971201)67:3<353::AID-JCB7>3.0.C0;2-V

Davis, E., Loiacono, R., \& Summers, R. J. (2008). The rush to adrenaline: Drugs in sport acting on the $\beta$-adrenergic system. British Journal of Pharmacology, 154(3), 584-597. https://doi.org/10.1038/bjp.2008.164

Fajardo, G., Zhao, M., Berry, G., Wong, L.-J., Mochly-Rosen, D., \& Bernstein, D. (2011). B2-adrenergic receptors mediate cardioprotection through crosstalk with mitochondrial cell death pathways. Journal of Molecular and Cellular Cardiology, 51(5), 781-789. https://doi.org/10.1016/j.yjmcc.2011.06.019 
Freedman, N. J., \& Lefkowitz, R. J. (2004). Anti- $\beta 1$-adrenergic receptor antibodies and heart failure: Causation, not just correlation. Journal of Clinical Investigation, 113(10), 1379-1382. https://doi.org/10.1172/JCl200421748

Gonçalves, D. A. P., Silveira, W. A., Lira, E. C., Graça, F. A., Paula-Gomes, S., Zanon, N. M., Kettelhut, I. C., \& Navegantes, L. C. C. (2011). Clenbuterol suppresses proteasomal and lysosomal proteolysis and atrophy-related genes in denervated rat soleus muscles independently of Akt. American Journal of Physiology-Endocrinology and Metabolism, 302(1), E123-E133. https://doi.org/10.1152/ajpendo.00188.2011

Guimarães, S., \& Moura, D. (2001). Vascular adrenoceptors: An update. Pharmacological Reviews, 53(2), 319-356.

Head, B. P., Patel, H. H., Roth, D. M., Lai, N. C., Niesman, I. R., Farquhar, M. G., \& Insel, P. A. (2005). G-protein-coupled receptor signaling components localize in both sarcolemmal and intracellular caveolin-3-associated microdomains in adult cardiac myocytes. The Journal of Biological Chemistry, 280(35), 31036-31044. https://doi.org/10.1074/jbc.M502540200

Hostrup, M., Kalsen, A., Onslev, J., Jessen, S., Haase, C., Habib, S., Ørtenblad, N., Backer, V., \& Bangsbo, J. (2015). Mechanisms underlying enhancements in muscle force and power output during maximal cycle ergometer exercise induced by chronic $\beta 2$-adrenergic stimulation in men. Journal of Applied Physiology (Bethesda, Md.: 1985), 119(5), 475-486. https://doi.org/10.1152/japplphysiol.00319.2015

laccarino, G., Ciccarelli, M., Sorriento, D., Galasso, G., Campanile, A., Santulli, G., Cipolletta, E., Cerullo, V., Cimini, V., Altobelli, G. G., Piscione, F., Priante, O., Pastore, L., Chiariello, M., Salvatore, F., Koch, W. J., \& Trimarco, B. (2005). Ischemic neoangiogenesis enhanced by beta2-adrenergic receptor overexpression: A novel role for the endothelial adrenergic system. Circulation Research, 97(11), 1182-1189. https://doi.org/10.1161/01.RES.0000191541.06788.bb

Jean-Baptiste, G., Yang, Z., Khoury, C., Gaudio, S., \& Greenwood, M. T. (2005). Peptide and non-peptide G-protein coupled receptors (GPCRs) in skeletal muscle. Peptides, 26(8), 1528-1536. https://doi.org/10.1016/i.peptides.2005.03.011

Jenkins, N. D. M., Colquhoun, R. J., Tomko, P. M., Gradnigo, T., Magrini, M. A., Muddle, T. W. D., Fleming, S., Ferrell, M., \& El-Sohemy, A. (2018). Genetic variant in the $\beta 2$-adrenergic receptor (Arg16Gly) influences fat-free mass, muscle strength and motor unit behaviour in young men. Experimental Physiology, 103(12), 1645-1655. https://doi.org/10.1113/EP087145

Jessen, S., Onslev, J., Lemminger, A., Backer, V., Bangsbo, J., \& Hostrup, M. (2018). Hypertrophic effect of inhaled beta2 -agonist with and without concurrent exercise training: A randomized controlled trial. Scandinavian Journal of Medicine \& Science in Sports, 28(10), 2114-2122. https://doi.org/10.1111/sms.13221

Joassard, O. R., Amirouche, A., Gallot, Y. S., Desgeorges, M. M., Castells, J., Durieux, A.-C., Berthon, P., \& Freyssenet, D. G. (2013). Regulation of Akt-mTOR, ubiquitin-proteasome and autophagylysosome pathways in response to formoterol administration in rat skeletal muscle. The International Journal of Biochemistry \& Cell Biology, 45(11), 2444-2455. https://doi.org/10.1016/i.biocel.2013.07.019

Kamalakkannan, G., Petrilli, C. M., George, I., LaManca, J., McLaughlin, B. T., Shane, E., Mancini, D. M., \& Maybaum, S. (2008). Clenbuterol increases lean muscle mass but not endurance in patients with chronic heart failure. The Journal of Heart and Lung Transplantation: The Official Publication of the International Society for Heart Transplantation, 27(4), 457-461. https://doi.org/10.1016/j.healun.2008.01.013

Kim, J., Grotegut, C. A., Wisler, J. W., Li, T., Mao, L., Chen, M., Chen, W., Rosenberg, P. B., Rockman, H. A., \& Lefkowitz, R. J. (2018). $\beta$-arrestin 1 regulates $\beta 2$-adrenergic receptor-mediated skeletal 
muscle hypertrophy and contractility. Skeletal Muscle, 8. https://doi.org/10.1186/s13395-018-0184$\underline{8}$

Kim, J., Grotegut, C. A., Wisler, J. W., Mao, L., Rosenberg, P. B., Rockman, H. A., \& Lefkowitz, R. J. (2020). The $\beta$-arrestin-biased $\beta$-adrenergic receptor blocker carvedilol enhances skeletal muscle contractility. Proceedings of the National Academy of Sciences, 117(22), 12435-12443. https://doi.org/10.1073/pnas.1920310117

Koopman, R., Gehrig, S. M., Léger, B., Trieu, J., Walrand, S., Murphy, K. T., \& Lynch, G. S. (2010). Cellular mechanisms underlying temporal changes in skeletal muscle protein synthesis and breakdown during chronic \{beta\}-adrenoceptor stimulation in mice. The Journal of Physiology, 588(Pt 23), 4811-4823. https://doi.org/10.1113/jphysiol.2010.196725

Koziczak-Holbro, M., Rigel, D. F., Dumotier, B., Sykes, D. A., Tsao, J., Nguyen, N.-H., Bösch, J., Jourdain, M., Flotte, L., Adachi, Y., Kiffe, M., Azria, M., Fairhurst, R. A., Charlton, S. J., Richardson, B. P., Lach-Triflieff, E., Glass, D. J., Ullrich, T., \& Hatakeyama, S. (2019). Pharmacological Characterization of a Novel 5-Hydroxybenzothiazolone-Derived B2-Adrenoceptor Agonist with Functional Selectivity for Anabolic Effects on Skeletal Muscle Resulting in a Wider Cardiovascular Safety Window in Preclinical Studies. The Journal of Pharmacology and Experimental Therapeutics, 369(2), 188-199. https://doi.org/10.1124/jpet.118.255307

Kuramoto, N., Nomura, K., Kohno, D., Kitamura, T., Karsenty, G., Hosooka, T., \& Ogawa, W. (2021). Role of PDK1 in skeletal muscle hypertrophy induced by mechanical load. Scientific Reports, 11(1), 3447. https://doi.org/10.1038/s41598-021-83098-z

Le Panse, B., Collomp, K., Portier, H., Lecoq, A.-M., Jaffre, C., Beaupied, H., Richard, O., Benhamou, L., De Ceaurriz, J., \& Courteix, D. (2005). Effects of short-term salbutamol ingestion during a Wingate test. International Journal of Sports Medicine, 26(7), 518-523. https://doi.org/10.1055/s-2004-821224

Li, Y., Yuan, H., Sun, L., Zhou, Q., Yang, F., Yang, Z., \& Liu, D. (2019). ß2-Adrenergic Receptor Gene Polymorphisms Are Associated with Cardiovascular Events But not All-Cause Mortality in Coronary Artery Disease Patients: A Meta-Analysis of Prospective Studies. Genetic Testing and Molecular Biomarkers, 23(2), 124-137. https://doi.org/10.1089/gtmb.2018.0153

Meszaros, J. G., Gonzalez, A. M., Endo-Mochizuki, Y., Villegas, S., Villarreal, F., \& Brunton, L. L. (2000). Identification of $\mathrm{G}$ protein-coupled signaling pathways in cardiac fibroblasts: Cross talk between $\mathrm{G}(\mathrm{q})$ and G(s). American Journal of Physiology. Cell Physiology, 278(1), C154-162. https://doi.org/10.1152/aipcell.2000.278.1.C154

Minetti, G. C., Feige, J. N., Rosenstiel, A., Bombard, F., Meier, V., Werner, A., Bassilana, F., Sailer, A. W., Kahle, P., Lambert, C., Glass, D. J., \& Fornaro, M. (2011). Gai2 Signaling Promotes Skeletal Muscle Hypertrophy, Myoblast Differentiation, and Muscle Regeneration. Science Signaling, 4(201), ra80-ra80. https://doi.org/10.1126/scisignal.2002038

Navegantes, L. C., Resano, N. M. Z., Baviera, A. M., Migliorini, R. H., \& Kettelhut, I. C. (2004). Effect of sympathetic denervation on the rate of protein synthesis in rat skeletal muscle. American Journal of Physiology. Endocrinology and Metabolism, 286(4), E642-647. https://doi.org/10.1152/ajpendo.00371.2003

Navegantes, L. C., Resano, N. M., Migliorini, R. H., \& Kettelhut, I. C. (2000). Role of adrenoceptors and CAMP on the catecholamine-induced inhibition of proteolysis in rat skeletal muscle. American Journal of Physiology. Endocrinology and Metabolism, 279(3), E663-668. https://doi.org/10.1152/ajpendo.2000.279.3.E663

Navegantes, L. C., Resano, N. M., Migliorini, R. H., \& Kettelhut IC, null. (2001). Catecholamines inhibit $\mathrm{Ca}(2+)$-dependent proteolysis in rat skeletal muscle through beta(2)-adrenoceptors and cAMP. American Journal of Physiology. Endocrinology and Metabolism, 281(3), E449-454. https://doi.org/10.1152/ajpendo.2001.281.3.E449 
Noh, H., Yu, M. R., Kim, H. J., Lee, J. H., Park, B.-W., Wu, I.-H., Matsumoto, M., \& King, G. L. (2017). Beta 2-adrenergic receptor agonists are novel regulators of macrophage activation in diabetic renal and cardiovascular complications. Kidney International, 92(1), 101-113. https://doi.org/10.1016/i.kint.2017.02.013

Pellegrino, M. A., D'Antona, G., Bortolotto, S., Boschi, F., Pastoris, O., Bottinelli, R., Polla, B., \& Reggiani, C. (2004). Clenbuterol antagonizes glucocorticoid-induced atrophy and fibre type transformation in mice. Experimental Physiology, 89(1), 89-100. https://doi.org/10.1113/expphysiol.2003.002609

Rang, H. P., Dale, M. M., Ritter, J. M., \& Moore, P. (2003). Pharmacology. Churchill Livingstone.

Rybin, V. O., Xu, X., Lisanti, M. P., \& Steinberg, S. F. (2000). Differential targeting of beta -adrenergic receptor subtypes and adenylyl cyclase to cardiomyocyte caveolae. A mechanism to functionally regulate the CAMP signaling pathway. The Journal of Biological Chemistry, 275(52), 41447-41457. https://doi.org/10.1074/jbc.M006951200

Santos, I. N., \& Spadari-Bratfisch, R. C. (2006). Stress and cardiac beta adrenoceptors. Stress (Amsterdam, Netherlands), 9(2), 69-84. https://doi.org/10.1080/10253890600771858

Sato, S., Shirato, K., Tachiyashiki, K., \& Imaizumi, K. (2011). Muscle Plasticity and $\beta 2$-Adrenergic Receptors: Adaptive Responses of $\beta 2$-Adrenergic Receptor Expression to Muscle Hypertrophy and Atrophy. Journal of Biomedicine and Biotechnology, 2011. https://doi.org/10.1155/2011/729598

Scholpa, N. E., Simmons, E. C., Tilley, D. G., \& Schnellmann, R. G. (2019). B2-adrenergic receptormediated mitochondrial biogenesis improves skeletal muscle recovery following spinal cord injury. Experimental Neurology, 322, 113064. https://doi.org/10.1016/i.expneurol.2019.113064

Spadari, R. C., Cavadas, C., de Carvalho, A. E. T. S., Ortolani, D., de Moura, A. L., \& Vassalo, P. F. (2018). Role of Beta-adrenergic Receptors and Sirtuin Signaling in the Heart During Aging, Heart Failure, and Adaptation to Stress. Cellular and Molecular Neurobiology, 38(1), 109-120. https://doi.org/10.1007/s10571-017-0557-2

Storch, C. H., \& Hoeger, P. H. (2010). Propranolol for infantile haemangiomas: Insights into the molecular mechanisms of action. The British Journal of Dermatology, 163(2), 269-274. https://doi.org/10.1111/j.1365-2133.2010.09848.x

Toledo, M., Busquets, S., Penna, F., Zhou, X., Marmonti, E., Betancourt, A., Massa, D., López-Soriano, F. J., Han, H. Q., \& Argilés, J. M. (2016). Complete reversal of muscle wasting in experimental cancer cachexia: Additive effects of activin type II receptor inhibition and $\beta-2$ agonist. International Journal of Cancer, 138(8), 2021-2029. https://doi.org/10.1002/ijc.29930

Wang, Q., Liu, Y., Fu, Q., Xu, B., Zhang, Y., Kim, S., Tan, R., Barbagallo, F., West, T., Anderson, E., Wei, W., Abel, E. D., \& Xiang, Y. K. (2017). Inhibiting Insulin-Mediated ß2-Adrenergic Receptor Activation Prevents Diabetes-Associated Cardiac Dysfunction. Circulation, 135(1), 73-88. https://doi.org/10.1161/CIRCULATIONAHA.116.022281

Woo, A. Y. H., \& Xiao, R. (2012). $\beta$-Adrenergic receptor subtype signaling in heart: From bench to bedside. Acta Pharmacologica Sinica, 33(3), 335-341. https://doi.org/10.1038/aps.2011.201

Wright, P. T., Nikolaev, V. O., O'Hara, T., Diakonov, I., Bhargava, A., Tokar, S., Schobesberger, S., Shevchuk, A. I., Sikkel, M. B., Wilkinson, R., Trayanova, N. A., Lyon, A. R., Harding, S. E., \& Gorelik, J. (2014). Caveolin-3 regulates compartmentation of cardiomyocyte beta2-adrenergic receptormediated cAMP signaling. Journal of Molecular and Cellular Cardiology, 67, 38-48. https://doi.org/10.1016/i.yimcc.2013.12.003

Xia, K., Ding, R., Zhang, Z., Li, W., Shang, X., Yang, X., Wang, L., \& Zhang, Q. (2017). The association of eight potentially functional polymorphisms in five adrenergic receptor-encoding genes with myocardial infarction risk in Han Chinese. Gene, 624, 43-49. https://doi.org/10.1016/i.gene.2017.04.045 
Xiang, Y., Rybin, V. O., Steinberg, S. F., \& Kobilka, B. (2002). Caveolar localization dictates physiologic signaling of beta 2-adrenoceptors in neonatal cardiac myocytes. The Journal of Biological Chemistry, 277(37), 34280-34286. https://doi.org/10.1074/jbc.M201644200

Yimlamai, T., Dodd, S. L., Borst, S. E., \& Park, S. (2005). Clenbuterol induces muscle-specific attenuation of atrophy through effects on the ubiquitin-proteasome pathway. Journal of Applied Physiology (Bethesda, Md.: 1985), 99(1), 71-80. https://doi.org/10.1152/japplphysiol.00448.2004

Zhu, W. Z., Zheng, M., Koch, W. J., Lefkowitz, R. J., Kobilka, B. K., \& Xiao, R. P. (2001). Dual modulation of cell survival and cell death by beta(2)-adrenergic signaling in adult mouse cardiac myocytes. Proceedings of the National Academy of Sciences of the United States of America, 98(4), 16071612. https://doi.org/10.1073/pnas.98.4.1607

Ziegler, O., Anderson, K., Liu, Y., Ehsan, A., Fingleton, J., Sodha, N., Feng, J., \& Sellke, F. W. (2020). Skeletal muscle microvasculature response to $\beta$-adrenergic stimuli is diminished with cardiac surgery. Surgery, 167(2), 493-498. https://doi.org/10.1016/j.surg.2019.07.018 